\title{
Polinização e biologia floral de Clusia arrudae Planchon \& Triana (Clusiaceae) na Serra da Calçada, município de Brumadinho, MG
}

\author{
ROSELAINI M. CARMO ${ }^{1}$ e EDIVANI V. FRANCESCHINELLI ${ }^{1,2}$
}

(recebido: 2 de maio de 2001; aceito: 5 de junho de 2002)

\begin{abstract}
Pollination and floral biology of Clusia arrudae Planchon \& Triana (Clusiaceae) in Serra da Calçada, Brumadinho, MG). The floral biology and pollination of Clusia arrudae was studied at "Serra da Calçada". C. arrudae does not present apomixis even when resin is deposited on the stigma. Fruits developed from flowers manually pollinated produced more seeds (6.3 per locule in average) than fruits developed from flowers naturally pollinated (4.3 seeds per locule). Blooming of $C$. arrudae peaks between December and mid-February. Male and female individuals of $C$. arrudae produce flowers daily; however, each three days there is a synchronized anthesis peak within the population. Sexual rate in the population is $1: 1$, with male plants producing more flowers than female. Male flowers produce about $11 \times 10^{6}$ pollen grains along the three day anthesis. Most of them (about 66\%) are presented on the first day. The stigmas of female flowers remain receptive for three days or four days when pollination does not happen in the first three days. Flowers of $C$. arrudae were visited by six species of bees for pollen or resin collection. Workers of Apis mellifera and Trigona spinipes, and females of Xylocopa frontalis and Neocorynura sp. visited male flowers for pollen; workers of Trigona spinipes also visited female flower for resin collection. Workers of Melipona quadrifasciata and females of Eufriesea nigrohirta were observed collecting resin on both male and female flowers. Due to its frequency and behavior on flowers of both sexes, E. nigrohirta is the main pollinator of C. arrudae at "Serra da Calçada".
\end{abstract}

RESUMO - (Polinização e biologia floral de Clusia arrudae Planchon \& Triana (Clusiaceae) na Serra da Calçada, Brumadinho, MG). A biologia floral e a polinização de Clusia arrudae foi estudada na Serra da Calçada. C. arrudae não apresenta apomixia mesmo com a deposição de resina nos estigmas. Frutos desenvolvidos a partir de flores polinizadas manualmente produziram mais sementes (6,3 sementes por lóculo) do que frutos desenvolvidos a partir de flores polinizadas naturalmente (4,3 sementes por lóculo). O pico de floração ocorre de dezembro a meados de fevereiro. Plantas masculinas e femininas produzem flores diariamente; todavia, a cada três dias ocorre um pico de anteses que é sincronizado na população. A razão sexual da população é de 1:1, com plantas masculinas produzindo uma maior quantidade de flores que plantas femininas. Flores masculinas produzem cerca de $11 \times 10^{6}$ grãos de pólen no decorrer de três dias. A maioria dos grãos $(66 \%)$ é apresentada no primeiro dia. Os estigmas das flores femininas permanecem receptivos por três dias ou quatro dias quando não ocorre polinização entre o primeiro e o terceiro dias. Flores de C. arrudae foram visitadas por seis espécies de abelhas para coleta de pólen e/ou resina. Operárias de Apis mellifera e Trigona spinipes, fêmeas de Xylocopa frontalis e Neocorynura sp. visitaram flores masculinas para coleta de pólen; operárias de T. spinipes foram também observadas coletando resina em flores femininas. Operárias de Melipona quadrifasciata e fêmeas de Eufriesea nigrohirta foram observadas coletando resina em flores femininas e masculinas. Devido à sua freqüência e comportamento nas flores femininas e masculinas, E. nigrohirta é o polinizador principal de $C$. arruda na Serra da Calçada.

Key words - Clusia arrudae, Eufriesea nigrohirta, floral biology, pollination

\section{Introdução}

O gênero Clusia ocorre na região neotropical e reúne cerca de 250 espécies semi-epífitas, trepadeiras, arbustivas e arbóreas (Bittrich \& Amaral 1996, 1997), 67 das quais ocorrem no Brasil. A maioria das espécies é dióica, com raras ocorrências de plantas monóicas (Lopes \& Machado 1998).

\footnotetext{
1. Universidade Federal de Minas Gerais, ICB, Departamento de Botânica. Caixa Postal 486, 30161-970 Belo Horizonte, MG, Brasil.

2._Autor para correspondência: edivani@icb.ufmg.br
}

Embora ocorram algumas espécies que oferecem néctar ou pólen como recurso para o polinizador (Bittrich \& Amaral 1997), a maioria das espécies do gênero secreta grande quantidade de resina, que é um recurso raro para os polinizadores, sendo registrado apenas nos gêneros Clusiella, Clusia (Clusiaceae) e Dalechampia (Euphorbiaceae) (Armbruster 1984). Estas plantas possuem polinizadores altamente específicos (Bittrich \& Amaral 1997). Nas flores femininas de Clusia esta resina é produzida por um anel de estaminódios que circunda o gineceu; nas flores masculinas, a resina é secretada pela expansão do tecido conectivo da antera ou por um aglomerado de estaminódios circundados por estames férteis. Skutch, 
em 1971, foi o primeiro a observar que as flores de algumas espécies de Clusia ofereciam resina como recurso para os visitantes (Bittrich \& Amaral 1996).

Plantas produtoras de resina têm um papel importante na comunidade, por fornecerem matéria prima básica para a construção de ninhos de várias espécies de abelhas, que, por sua vez, podem estar coletando alimento e, desta forma, realizando a polinização em outras espécies vegetais que dependem da polinização cruzada. Sendo assim, estas espécies vegetais apresentam dependência indireta das plantas produtoras de resina para sua reprodução (Armbruster 1984).

Embora já tenha sido sugerido que a resina floral seja coletada por meliponíneos pelo seu valor energético/nutritivo (Ramírez \& Gómez 1978), Armbruster (1984) sugere que isto é muito pouco provável. Vários autores, no entanto, assumem que essas abelhas utilizam este recurso para a construção de ninhos (p. ex. Armbruster 1984, Simpson \& Neff 1981, Bittrich \& Amaral 1996) e é o que ocorre também com as abelhas da tribo Euglossini (Kimsey 1982) e Anthidiini (Michener 2000) que utilizam esta substância na construção de células dos ninhos.

Além da função estrutural, a resina usada nos ninhos ainda serve como proteção contra invasores (Simpson \& Neff 1981) como ocorre nos ninhos de meliponineos onde se encontram depósitos desta substância (Nogueira-Neto 1997). Também, possivelmente, a resina desempenha função anti-microbiana (Armbruster 1984, Oliveira et al. 1996, Lokvam \& Braddock 1999) o que reduziria os riscos de patogenias nos ninhos.

Nenhum registro foi encontrado de estudos sobre a biologia floral e polinização de Clusia arrudae Planchon \& Triana. Sendo assim é de grande importância um estudo que forneça dados sobre a estratégia reprodutiva desta espécie.

Este trabalho teve como objetivo verificar a estratégia e o sistema reprodutivos de Clusia arrudae, incluindo informações sobre padrão de floração, razão sexual e distribuição da população, apresentação, viabilidade e tamanho do pólen, período de receptividade do estigma em flores femininas e produção de pólen em flores masculinas, visitantes florais e possíveis polinizadores.

\section{Material e métodos}

Os dados foram coletados na Serra da Calçada, que é uma das muitas pequenas serras que constituem a Serra da
Moeda, no município de Brumadinho, em Minas Gerais (200' 36" S e 4'59'00" W e aproximadamente $1.480 \mathrm{~m}$ de altitude). A vegetação predominante no local é o campo rupestre sobre solo de "canga".

A população de Clusia arrudae Planchon \& Triana estudada possui 46 plantas femininas e 49 plantas masculinas em uma área de aproximadamente 2,5 ha, sendo esta a única população da espécie na área estudada.

As observações referentes ao período de floração foram feitas de dezembro de 1999 a novembro de 2000. Demais observações e experimentos foram realizados no período de 10 de janeiro a 22 de julho de 2000 , quando os últimos frutos dos experimentos foram coletados.

Sistema reprodutivo - Para verificação da ocorrência de apomixia foram ensacados botões de plantas femininas, em pré-antese, com sacos de nylon medindo $10 \times 10 \times 14 \mathrm{~cm}$. O tamanho e a forma desses sacos permitem abertura normal das pétalas, evitando que elas fiquem coladas aos estigmas. $\mathrm{O}$ teste de apomixia foi realizado com e sem deposição de resina de flores masculinas nos estigmas, como sugerido por Correia (1983).

Foram realizadas polinizações manuais de flores e comparado o número médio de sementes produzidas por lóculo neste tratamento com o obtido a partir da polinização natural de flores expostas (controle). Após a polinização manual, as flores foram ensacadas novamente. Para análise desses dados foi realizado um teste $t$ com variância estimada separadamente porque não houve homogeneidade de variância entre os tratamentos.

Para cada experimento citado acima (apomixia, polinização manual e controle), foram feitas 20 repetições distribuídas aleatoriamente entre 10 plantas. Do tratamento de apomixia com deposição de resina no estigma, entretanto, foram feitas apenas nove repetições.

Durante seu desenvolvimento, os frutos provenientes de flores submetidas aos tratamentos acima, permaneceram protegidos nos sacos de nylon para evitar eventuais danos por herbívoros ou perda de sementes, em caso de ocorrer deiscência antes de sua coleta. A coleta dos frutos e contagem das sementes foram feitas cinco meses após a realização dos experimentos, quando o seu amadurecimento ainda não estava completo.

Padrão de floração - O número de flores em três plantas femininas e três plantas masculinas foi contado diariamente entre os dias 18/01/2000 e 06/03/2000, exceto em dias de chuva. Essas contagens foram feitas, após esse período, também durante as visitas esporádicas à área de estudo, até o mês de julho.

Razão sexual - Foram contados e mapeados os indivíduos adultos de $C$. arrudae da população estudada. Foram consideradas adultas aquelas plantas que já haviam atingido a fase reprodutiva (plantas que floriram no ano).

Apresentação do pólen - Para avaliar a quantidade de pólen apresentada diariamente pelas flores masculinas, foram ensacados 16 botões em pré-antese, para impedir o contato 
com visitantes florais. Os ramos contendo os botões ensacados foram presos com barbante a outros galhos para evitar que a flor ensacada fosse muito agitada pelo vento, perdendo grãos de pólen. Foram usados, para este experimento, apenas botões que abririam na manhã do ensacamento.

Ao final do primeiro dia (aproximadamente às 17:00 h), quatro das 16 flores ensacadas foram lavadas, uma a uma, com álcool $70 \%$, com o auxílio de uma pisseta para retirar todo o pólen liberado pelas anteras. O álcool com o pólen foi recolhido diretamente em um becker e, posteriormente, acondicionado em frascos de plástico, acrescido de pequena quantidade adicional de álcool usada para lavar o becker. Este procedimento foi repetido nos três dias seguintes com as flores restantes. A quantidade de pólen em cada flor foi estimada de acordo com a técnica sugerida por Maêda (1985) contando-se os grãos presentes nos campos de A a E do hemacitômetro.

A observação e contagem foram feitas ao microscópio óptico (aumento $=10 \mathrm{X}$ ) e a estimativa foi realizada usandose a seguinte fórmula:

$$
\mathrm{x}=\mathrm{n} .2000 . \mathrm{v}
$$

onde $\mathrm{x}=$ quantidade total de grãos na flor, $\mathrm{n}=\mathrm{a}$ soma $\mathrm{da}$ quantidade de grãos encontrados nos cinco campos do hemacitômetro, e v = volume total da solução em mililitros.

A quantidade de grãos de pólen liberada a cada dia, por flor, foi estimada subtraindo-se do número de grãos contados, o número médio de grãos contados nos dias anteriores.

Viabilidade - A viabilidade dos grãos foi estimada através de método indireto por coloração com carmim acético (Dafni 1992). Por este método são considerados viáveis apenas os grãos corados. Para isso, foram montadas, separadamente, lâminas com grãos de pólen frescos de três flores, cada uma de uma planta distinta. A contagem de grãos de pólen corados e não corados foi feita em três campos visuais do microscópio, sendo feitas 10 repetições de cada amostra. Foram contados, em média, 48 grãos por amostra. Foi feito um teste $X^{2}$ para verificar se houve diferença significativa entre o número de grãos de pólen corados e não corados.

Período de receptividade do estigma - O período de receptividade do estigma foi verificado in vivo, através de polinização manual. As flores submetidas a este tratamento foram ensacadas no período de pré-antese e permaneceram ensacadas até o momento da polinização, para evitar o contato com visitantes florais. Foram polinizadas, manualmente, seis flores no primeiro dia de abertura, seis flores no segundo dia e assim por diante, durante quatro dias. Foi realizada, ainda, a polinização manual em quatro flores no quinto dia de abertura. Este número se deve ao pequeno número de flores disponíveis, já que este tratamento foi realizado em período de baixa floração. Após a polinização, as flores foram ensacadas novamente, permanecendo assim até a coleta dos frutos.

Visitantes florais - O número de visitantes observados e o comportamento de cada um deles nas flores masculinas e femininas foram registrados (incluindo data e horário da observação) em períodos destinados exclusivamente à coleta desses dados e, também, nos períodos destinados aos outros experimentos.

A freqüência de visitas em flores femininas e masculinas foi estimada dividindo-se o número de visitas pelo número de flores usadas nas observações e pelo tempo de observação (em minutos). Nas plantas femininas a contagem dos visitantes foi realizadas em três plantas, tomando-se em cada uma três períodos de 15 minutos de observação (intervalo de um hora entre cada período). Foram observadas todas as flores presentes em um lado da planta. Nas flores masculinas a contagem foi feita em três intervalos de 10 minutos em cinco flores de cada planta (também foram usadas três plantas). As contagens tanto em plantas femininas quanto masculinas foram realizadas em períodos de maior atividade das abelhas (8:30 às 11:30 h).

Foi realizada uma pesquisa nas coleções do Laboratório de Sistemática e Ecologia de Abelhas do Departamento de Zoologia da UFMG e do Departamento de Biologia Animal da UFV para verificar as datas e os locais de coleta de exemplares de Eufriesea nigrohirta.

Alguns indivíduos de cada espécie foram coletados para identificação no laboratório com o auxílio de chaves taxonômicas e comparação com espécimes identificados previamente por especialistas. Tais espécimes foram depositados na coleção do Laboratório de Sistemática e Ecologia de Abelhas, Departamento de Zoologia, Instituto de Ciências Biológicas da Universidade Federal de Minas Gerais.

\section{Resultados}

Clusia arrudae Planchon \& Triana é uma planta dióica, de porte arbóreo com distribuição nas serras de Minas Gerais e Rio de Janeiro (V. Bittrich, dados não publicados), sendo comum no campo rupestre da Serra da Calçada. Suas flores são brancas, com oito pétalas. As flores femininas possuem estigmas dilatados e amarelos, que podem variar de cinco a oito, em uma mesma planta. $\mathrm{O}$ número de estigmas corresponde sempre ao número de carpelos no ovário de cada flor. As flores masculinas possuem inúmeras anteras esbranquiçadas, densamente distribuídas em torno de estigmas não funcionais que, também, variam entre cinco e oito por flor. Os frutos são deiscentes, esféricos, podendo conter até nove sementes por lóculo. As sementes, quando maduras, são avermelhadas e medem até $0,7 \mathrm{~cm}$ de diâmetro. Tanto flores femininas quanto masculinas possuem um forte odor adocicado, principalmente pela manhã do primeiro dia da antese. A partir do segundo dia o odor se torna mais fraco e praticamente desaparece nos dias seguintes. Essas flores 
também podem refletir luz ultra violeta, o que evidencia a condição de melitófila.

Sistema reprodutivo - Nenhuma das flores submetidas ao tratamento de apomixia, com ou sem deposição de resina nos estigmas, desenvolveu frutos. Estas flores secaram e caíram 15 a 20 dias após o ensacamento. Frutos provenientes de flores submetidas à polinização manual produziram, em média 6,3 sementes por loco, enquanto flores submetidas à polinização natural (controle) deram origem a frutos que produziram, em média, 4,3 sementes por loco (teste $t$ com variância estimada separadamente: $\mathrm{gl}=17,67 ; \mathrm{t}=-5,15$; $\mathrm{p}>0,001)$.

Padrão de floração - O pico da floração de Clusia arrudae ocorre de dezembro a meados de fevereiro. No entanto, algumas plantas continuam emitindo esporadicamente poucas flores (uma ou duas de cada vez) durante todo o ano, podendo haver períodos em que não há nenhuma flor em nenhuma das plantas da população. As flores produzidas fora do período de pico, são principalmente masculinas. As poucas flores femininas produzidas fora do período de pico, que foram marcadas, não desenvolveram frutos.

A antese de flores masculinas e femininas ocorre principalmente pela manhã, entre $7: 30$ e $9: 30 \mathrm{~h}$ entretanto até as 15:30 h, ainda é observada a abertura de alguns poucos botões masculinos.

Os indivíduos masculinos e femininos de C. arrudae produzem flores diariamente. Porém, a cada três dias, ocorre um pico de anteses, tanto de flores femininas quanto masculinas, que é sincronizado na população. Ou seja, um dia com grande número de anteses na população é seguido por dois dias com pequeno número de aberturas florais. Este padrão é observado no período de pico da floração, corrompendose com a diminuição da freqüência de produção de flores. A partir daí, podem-se passar mais de três dias sem que haja um pico de floração (figura 1).

Razão sexual - A razão sexual da população de C. arrudae na Serra da Calçada é de 1:1. No entanto, plantas masculinas produziram um maior número de flores por dia do que plantas femininas, nos dias observados (figura 2).

Apresentação e viabilidade dos grãos de pólen - As flores masculinas liberam pólen, espontaneamente, durante os três primeiros dias de antese. Cada flor produz, em média, aproximadamente $11 \times 10^{6}$ grãos de pólen, sendo a maioria deles (em média 66\%) apresentada no primeiro dia da antese. No segundo e terceiro dias são apresentados, em média, $22 \%$ e $12 \%$ do total dos grãos, respectivamente. Do total de grão liberados pelas anteras, aproximadamente $82 \%$ apresentaram coloração positiva pelo carmim acético, sendo aparentemente viáveis.

Período de receptividade do estigma - No primeiro dia de abertura das flores femininas suas corolas apresentam-se completamente brancas. As flores abertas há dois dias ainda estão bem semelhantes àquelas abertas há um dia, havendo apenas, em algumas flores, pequenas manchas escuras. No terceiro dia toda a corola já apresenta-se levemente amarelada e com uma maior quantidade de manchas escuras. No quarto dia de abertura a corola se apresenta murcha e com grande quantidade de manchas escuras. Flores polinizadas manualmente, para verificação do período de receptividade do estigma, produziram frutos quando polinizadas entre o primeiro e o quarto dias de antese.

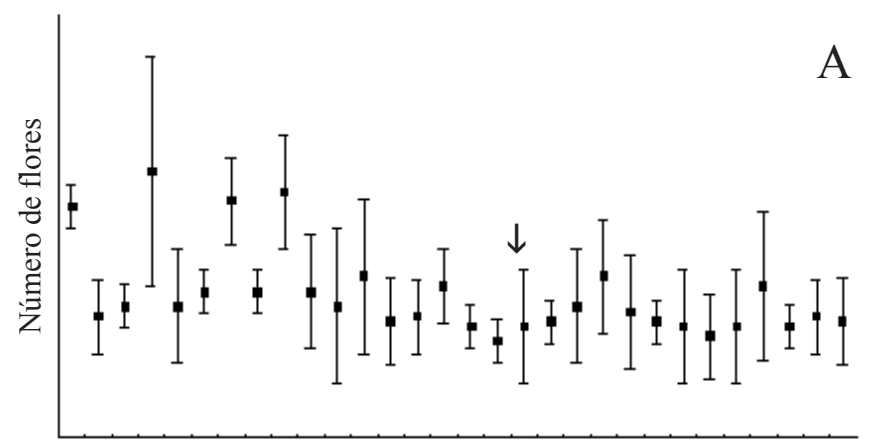

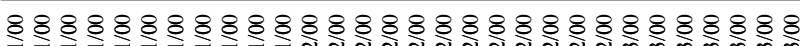

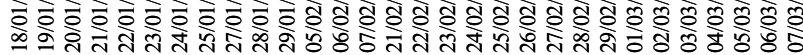

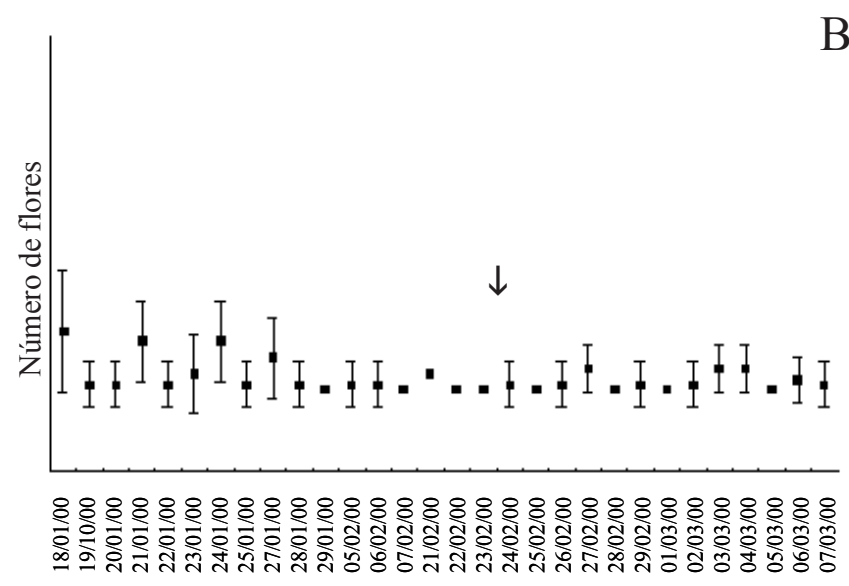

Figura 1. Média da quantidade de flores produzidas diariamente por plantas masculinas (A) e femininas (B) de Clusia arrudae durante os dias de experimento. Foram usadas três plantas de cada sexo para a contagem. No dia 26/01/2000 não houve coleta devido à chuva. As setas indicam o final do pico de floração da planta, quando o padrão no qual um dia com grande quantidade de flores é seguido por dois com poucas flores, deixa de ocorrer. 


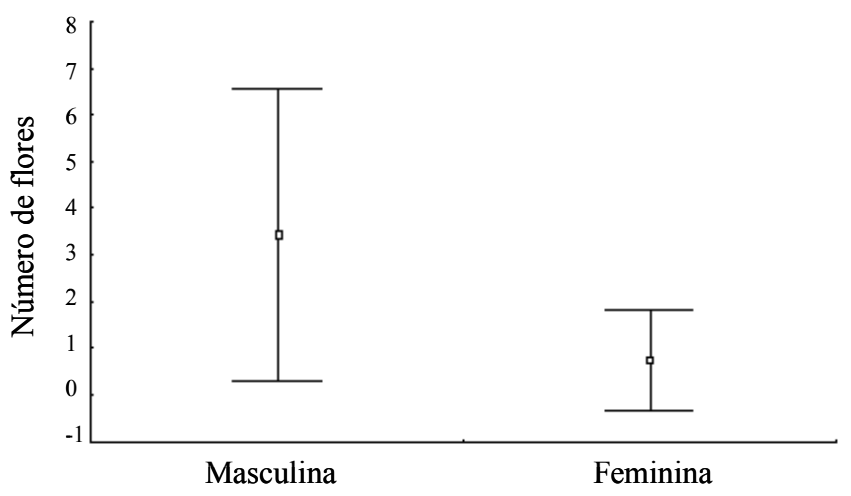

Figura 2. Número médio ( \pm erro padrão) de flores produzidas por dia por plantas masculinas e femininas de Clusia arrudae na Serra da Calçada. Os valores são as médias obtidas durante 30 dias de observação em três plantas de cada sexo.

No entanto, flores polinizadas até o terceiro dia após a antese, apresentaram, no quarto dia, estigmas escurecidos e menos úmidos do que aqueles que não haviam sido polinizados anteriormente. Nenhuma flor polinizada apenas no quinto dia após a abertura produziu fruto. Os estigmas de flores abertas há cinco dias apresentaram-se escurecidos e praticamente sem nenhuma umidade, mesmo quando polinizados nos dias anteriores. Sendo assim, estigmas das flores femininas, aparentemente, permanecem receptivos até o quarto dia, somente quando a flor não foi polinizada até o terceiro dia após a antese.

Produção de resina - Flores masculinas e femininas produzem grande quantidade de resina que é secretada por um anel de estaminódios não férteis no primeiro dia de abertura das flores. Desde os primeiros momentos da antese a flor já apresenta um anel de resina amarelada e viscosa, que se torna mais escura, menos viscosa e mais consistente a partir do quarto dia de antese.

Visitantes - As flores de Clusia arrudae foram visitadas por seis espécies de abelhas para coleta de pólen ou resina. As visitas ocorreram em sua grande maioria pela manhã, entre 7:30 e 11:30 h. Após esse horário e até aproximadamente as 14:00 h, houve poucas visitas de Apis mellifera e Trigona spinipes e, a partir daí, apenas visitas esporádicas.

Apis mellifera foi a espécie mais freqüente nas flores masculinas, procurando-as exclusivamente para a coleta de pólen. Durante suas visitas, as operárias dessa espécie, caminham, circulando sobre as anteras, coletando grande quantidade do pólen. Após períodos de recolhimento de pólen, as abelhas realizam pequenos vôos para retirar o pólen do corpo e acondicioná-lo na corbícula. Durante estes vôos, elas permanecem próximas à flor e, após o acondicionamento do pólen, podem retornar para a mesma flor ou pousar em outra para continuar a coleta. Apenas três operárias de $A$. mellifera foram observadas em flores femininas. Nestas visitas, houve apenas um toque, por uma das abelhas com a pata traseira em um dos oito estigmas da flor. Foram feitas, também, algumas observações de coleta de látex em galhos de plantas femininas, por operárias desta espécie.

Trigona spinipes foi a segunda espécie mais freqüente nas flores masculinas. Nestas visitas, suas operárias, coletaram apenas pólen, posicionando-se sobre as anteras e caminhando apenas em uma pequena parte da área coberta pelas mesmas. Nesta ocasião notou-se a ocorrência de grãos de pólen aderidos ao corpo das abelhas. Em flores femininas, T. spinipes foi a espécie mais freqüente, coletando resina. Nestas visitas, suas operárias se posicionavam sobre as pétalas ou o estigma. Neste caso, elas tocaram apenas um ou, mais raramente, dois estigmas dessas flores. A maioria das visitas de operárias de $T$. spinipes a flores femininas ocorreu depois do período de pico da floração (fevereiro), quando havia poucas flores masculinas e femininas. O número de grãos de pólen encontrado no corpo de cinco indivíduos de $T$. spinipes que foram coletadas visitando flores femininas para coleta de resina variou entre zero e cinco.

Eufriesea nigrohirta, cujas fêmeas visitaram flores masculinas apenas para coleta de resina, foi a terceira espécie mais freqüente nestas flores. Durante suas visitas, elas posicionaram-se sobre as anteras, recebendo grande quantidade de pólen no ventre do corpo. Em flores femininas, E. nigrohirta foi a segunda espécie mais freqüente. Suas fêmeas coletavam a resina com as mandíbulas e, durante pequenos vôos, bem próximos à flor, transferem a resina coletada para a corbícula. Nestas flores elas coletaram resina por todo o anel, realizando movimentos circulares sobre os estigmas. Nesta ocasião, ela visivelmente tocou todos os estigmas com a parte ventral do corpo. Devido ao comportamento das fêmeas de E. nigrohirta na flores, esta abelha parece ser o polinizador mais eficiente e quase exclusivo de Clusia arrudae.

Fêmeas de Xylocopa frontalis foram observadas principalmente em visita às flores masculinas, onde coletaram apenas pólen. Durante o período de observação, foi registrada apenas uma visita desta abelha às flores femininas. Esta visita foi muito rápida e não foi possível observar o comportamento da abelha na flor.

Operárias de Melipona quadrifasciata também 
foram observadas em visitas às flores masculinas. Estas visitas foram destinadas à coleta de resina. M. quadrifasciata coletou a resina do anel com as mandíbulas e, posteriormente, a transferiu para a corbícula. Estas abelhas foram observadas visitando flores femininas apenas uma vez. Nesta visita, a operária tocou quatro dos sete estigmas da flor. Esta visita também foi destinada à coleta de resina e não foi possível observar se haviam grãos de pólen aderidos ao corpo da abelha.

Fêmeas de uma espécie não identificada de Neocorynura foram observadas seis vezes visitando flores masculinas para coleta de pólen. Nestas visitas, estas abelhas não caminharam sobre as anteras, apenas pousaram em uma pequena área ocupada pelas anteras ou sobre as pétalas, de onde elas coletam rapidamente o pólen. Não foi observada nenhuma visita de Neocorynura sp. às flores femininas (tabela 1).

A diminuição no número de flores produzidas por planta no decorrer dos experimentos, tanto em plantas femininas quanto masculinas, foi acompanhada pela diminuição na freqüência de Apis mellifera e Eufriesea nigrohirta em visitas por flor. A freqüência de $T$. spinipes nessas condições não variou muito não havendo grande diminuição no número de visitas por flor até o final do período de observação (figura 3). Outras abelhas tiveram freqüência baixa e não foi possível estabelecer um padrão na freqüência de visitação delas.

\section{Discussão}

A ausência de produção de frutos por apomixia em Clusia arrudae também foi observada em outras espécies deste gênero, como C. nemorosa (Lopes \& Machado 1998), C. insignis e C renggerioides (Bittrich \& Amaral 1997). Em C. arrudae o contato da resina com o estigma não é suficiente para promover o desenvolvimento de frutos. Embora tenha sido citada a ocorrência de apomixia em C. fluminensis e C. lanceolata, estimulada pela deposição de resina de flores masculinas nos estigmas (Correia 1983), posteriormente foi demostrado que em C. lanceolata a resina pura não pode estimular a produção de frutos (Correia et al. 1999). No caso de C. fluminensis, foram também realizados experimentos nos quais houve deposição de resina filtrada das flores masculinas nos estigmas e também não houve produção de frutos (Bittrich, dados não publicados). Sendo assim, não existe nenhum caso demostrado, para o gênero, de apomixia estimulada pelo contato de resina de flores masculinas nos estigmas. Desta forma, por não apresentar apomixia e por ser dióica, $C$. arrudae é totalmente dependente de agentes polinizadores para sua reprodução sexuada.

Quanto à razão sexual da população estudada, os dados obtidos estão de acordo com a expectativa de Opler \& Bawa (1978), segundo os quais as espécies dióicas geralmente apresentam razão sexual de 1:1. Segundo estes autores existem evidencias de que a produção de sementes em plantas polinizadas por animais seja maximizada se plantas masculinas e femininas aparecem em quantidades semelhantes. A diferença entre o número de flores masculinas e femininas também foi observada em várias outras espécies e está de acordo com a sugestão de Willson \& Ågren (1989) de que plantas masculinas geralmente apresentam mais flores que plantas femininas. Segundo

Tabela 1. Tipo de recurso coletado por cada espécie de visitante e freqüência de visitantes em flores masculinas e femininas de Clusia arrudae. Para as espécies menos freqüentes, os valores entre parênteses são os números totais de abelhas observadas em visita às flores ao longo de todo o período de estudo, fora de períodos destinados à contagem de abelhas.

\begin{tabular}{|c|c|c|c|c|c|}
\hline \multirow[t]{2}{*}{ Abelha visitante } & \multicolumn{2}{|c|}{ Recurso coletado } & \multicolumn{3}{|c|}{$\begin{array}{l}\text { Freqüência de visitas } \\
\text { (abelhas/minuto/flor) }\end{array}$} \\
\hline & Pólen & Resina & Masculina & Femin & ina \\
\hline Apis mellifera & Sim & Não & 3 & 0 & $(2)^{*}$ \\
\hline Eufriesea nigrohirta & Não & Sim & $0,001 \quad(8)$ & 0,01 & (11) \\
\hline Melipona quadrifasciata & Não & Sim & $0,001 \quad(4)$ & & $(1)$ \\
\hline Neocorynura sp. & Sim & Não & $0,002 \quad(5)$ & 0 & \\
\hline Trigona spinipes & Sim & Sim & 1,7 & 0,03 & (13) \\
\hline Xylocopa frontalis & Sim & Não & (6) & 0 & (1) \\
\hline
\end{tabular}

* Visitas muito curtas e sem contato com estigma (visitas por engano). 


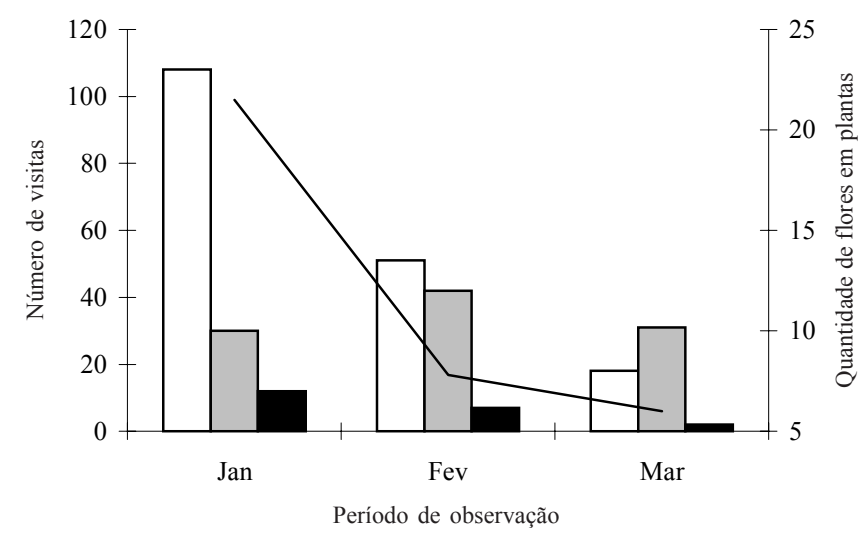

Figura 3. Freqüência de visitas realizadas pelos três principais visitantes ( $\square=$ Apis mellifera; $\square=$ Trigona spinipes; $\mathbf{\square}=$ Eufriesea nigrohirta) em flores masculinas e femininas de Clusia arrudae na Serra da Calçada (eixo primário) e número de flores produzidas nos meses de observação (linha contínua - eixo secundário).

Opler \& Bawa (1978), a seleção natural tende a favorecer este padrão que proporciona maior eficiência na polinização, dispersão de pólen e produção de sementes. Em Clusia pusilla existe um maior número de flores femininas que masculinas. No entanto nesta espécie o único recurso oferecido aos visitantes é o pólen. As abelhas visitam as flores femininas, por engano "mistake-pollination" atraídas pelo odor e morfologia que são semelhantes aos das flores masculinas (Bittrich \& Amaral 1996). Maior número de flores femininas, provavelmente, se faz necessário devido ao comportamento e ao curto período de tempo que as abelhas permanecem em flores femininas nos casos de "polinização por engodo".

O horário de abertura da maioria das flores de Clusia arrudae coincide com o horário de início da atividade da maioria das abelhas, que ocorre entre 8:00 e 9:00 h (Käpylä 1974).

O padrão observado em Clusia arrudae, em que a cada três dias se observa um pico de abertura de botões florais masculinos e femininos parece não ter sido registrado anteriormente para o gênero e é raro na literatura. Um padrão semelhante de picos sincronizados de floração foi detectado em Vellozia squamata (Oliveira et al. 1991). Este pico de abertura dos botões em $C$. arrudae parece estar relacionado com período em que as flores femininas permanecem receptivas e em que as flores masculinas mantém a liberação dos grãos de pólen.

Como já observado anteriormente (Armbruster 1984), a resina floral não é retirada totalmente em poucas visitas e as abelhas podem retornar várias vezes às mesmas flores nos dias seguintes à antese para coletá la. A permanência desse recurso na flor de C. arrudae pode estar garantindo sua atratividade durante todo o período em que ela permanece receptiva. Esta sugestão encontra base na afirmação de Bawa (1983), de que período em que uma flor permanece receptiva pode ter relação com o tipo de recurso oferecido.

O período relativamente grande em que as flores de Clusia arrudae permanecem abertas pode constituir uma vantagem para a planta já que, segundo Silveira (dados não publicados), Eufriesea nigrohirta, o polinizador quase exclusivo desta espécie na área estudada, é uma abelha relativamente rara. Sendo assim, quanto mais tempo durar uma flor, maior a probabilidade dela ser visitada pelo polinizador.

O fato do pólen de $C$. arrudae ser apresentado aos poucos, no decorrer de todo o dia, num período de três dias, pode possibilitar o contato do pólen com o polinizador em qualquer momento que haja a visita, não sendo possível que um único visitante carregue todo o pólen em uma única ou poucas visitas. Segundo Thomson \& Thomson (1992), o padrão de apresentação de pólen pode afetar o sucesso reprodutivo masculino da planta e, conseqüentemente, o sucesso reprodutivo feminino. Sendo assim, o padrão de apresentação do pólen em C. arrudae pode estar possibilitando que mais grãos de pólen cheguem em mais flores femininas, já que mesmo que uma abelha, em uma única visita, carregue grande quantidade de pólen, em uma próxima visita a flor possivelmente já terá liberado mais pólen. Desta forma várias abelhas terão contato com o pólen, aumentando assim a expectativa reprodutiva da planta.

A alta taxa de grãos de pólen viáveis apresentada por esta espécie foi similar à observada em Clusia nemorosa e em outras espécies dióicas (Lopes \& Machado 1998). Essa grande quantidade de grãos de pólen produzidos, em relação ao número de óvulos disponíveis na população, é uma característica de árvores tropicais (Opler \& Bawa 1978) e pode ser uma estratégia para aumentar as chances dos grãos chegarem aos estigmas, mesmo se houver grandes perdas.

O fato de flores polinizadas até o terceiro dia apresentarem estigmas escurecidos no quarto dia sugere que se as flores forem polinizadas nos três primeiros dias de abertura, no quarto dia elas já não estarão mais receptivas. A receptividade no quarto dia da antese garante uma maior chance da flor ser polinizada, caso ela não o tenha sido até o terceiro dia.

Na maioria das espécies de Clusia estudadas, como por exemplo C. grandiflora (Bittrich \& Amaral 1997) 
e C. nemorosa (Bittrich \& Amaral 1997, Lopes \& Machado 1998), as flores femininas e masculinas duram apenas um dia. Além disso, a diferença entre a durabilidade de flores femininas e masculinas (quatro e três dias, respectivamente) que ocasionalmente pode ocorrer em $C$. arrudae, foi observada também em C. renggerioides, onde flores femininas duram três dias e flores masculinas duram apenas um dia (Bittrich \& Amaral 1997). No entanto, estes autores não mencionam, se a duração das flores femininas está condicionada ou não à ocorrência da polinização, como aparentemente ocorre em C. arrudae, mas verificaram que a receptividade dos estigmas diminui com o decorrer dos dias.

$\mathrm{O}$ aumento na viscosidade da resina floral em C. arrudae após o terceiro dia de antese a torna mais difícil sua coleta. Isto pode constituir uma vantagem para a planta já que os polinizadores preferencialmente visitam flores novas, onde a coleta é mais fácil, e consequentemente entram em contato com o pólen. Sendo assim, as flores velhas que já não têm mais pólen, raramente serão visitadas.

A mistura de pólen e resina que ocorre em outras espécies do gênero como Clusia leprantha, C. renggerioides e C. panapanari, estudadas por Bittrich \& Amaral (1997) não ocorre em C. arrudae, já que nesta, os estaminódios produtores de resina se localizam separadamente dos estames férteis. A mistura da resina com o pólen provavelmente é uma estratégia que diminui a perda de pólen, mas requer uma certa especialização das flores femininas que produzem um líquido apolar que serve como diluente da resina, aumentando as chances do pólen coberto de resina entrar em contato com a papila estigmáticas (Bittrich \& Amaral 1997). No entanto em C. arrudae a localização dos estames férteis (no centro) em relação aos estaminódios produtores de resina (periféricos) facilitam o contato dos visitantes com o pólen no momento da coleta da resina, o que, provavelmente, também evita a perda do pólen.

Diferentemente do que ocorre em Clusia pusilla em que as abelhas coletam o pólen por vibração das anteras (Bittrich \& Amaral 1996), em C. arrudae o pólen é liberado espontaneamente pelas anteras. Aqui, talvez ocorra um processo semelhante àquele observado em C. schomburgkiana, em que o pólen é liberado pelo encolhimento dos sacos de pólen. Segundo Bittrich \& Amaral (1996) a diversidade no mecanismo de polinização no gênero se deve a grande diversidade em morfologia do androceu.

Apesar de Apis mellifera coletar resina para a produção de própolis (Bastos, dados não publicados), ela ignorou a resina disponível nas flores de $C$. arrudae na Serra da Calçada, diferentemente do que ocorreu nas flores de $C$. nemorosa, onde esta abelha coleta resina floral, participando da polinização da espécie (Lopes \& Machado 1998). Entre os fatores que poderiam contribuir para a ausência de coleta de resina por A. mellifera nas flores de C. arrudae na Serra da Calçada estariam propriedades físicas e/ou químicas inapropriadas ou fontes alternativas de resina mais abundante ou de qualidade melhor. Bastos (dados não publicados), a partir de análise da própolis verde, constatou que, na região de Minas Gerais, as coletas de resina por $A$. mellifera são realizadas principalmente nos ápices vegetativos de Baccharis spp. Este fato pode explicar a ausência de coleta de resina por esta abelha em C. arrudae na região da Serra da Calçada.

O maior número de sementes produzido por frutos provenientes de flores polinizadas manualmente pode estar indicando uma ineficiência na polinização natural no local de estudo. Esta ineficiência pode estar relacionada à quantidade excessiva de pólen retirada por Apis mellifera em suas visitas.

A diferença na quantidade de sementes presentes em lóculos de um mesmo fruto (de zero a oito) sugere que, em alguns casos, alguns estigmas receberam quantidades de grãos de pólen bem maior que em outros, podendo algum estigma não ter recebido pólen algum, ou que não foi depositado pólen suficiente nos estigmas para polinizar todos os óvulos existentes.

Espécies de Euglossini têm sido registradas como visitantes de todas as espécies de Clusia, na maioria dos casos, apenas para coleta de resina, como ocorre em C. arrudae. No entanto em C. insignis, que ocorre na Amazônia Central, a abelha Eufriesea purpurata pode coletar resina ou pólen. Neste caso, cada abelha coleta primeiro a resina e depois (horas depois da coleta da resina ou no dia seguinte) o pólen (Bittrich \& Amaral 1997). Provavelmente, neste caso, as abelhas após terminada a construção de uma célula do ninho iniciam a coleta do alimento para aprovisionamento na mesma espécie vegetal, por falta de uma fonte de pólen mais apropriada. No caso de E. nigrohirta em C. arrudae, após as abelhas construírem cada célula, provavelmente coletam o alimento para aprovisionamento em outras plantas da região.

O tamanho relativamente grande das abelhas Euglossini que aparecem como polinizadoras de várias espécies de Clusia, assim como ocorre em C. arrudae contradiz a proposta de Opler \& Bawa (1978) de que exista uma correlação entre plantas dióicas e 
polinizadores pequenos, pouco especializados.

Eufriesea nigrohirta, que é o polinizador mais eficiente e quase exclusivo de Clusia arrudae, é uma abelha relativamente rara e existem registros dela apenas nas regiões montanhosas do sudeste do Brasil (Silveira \& Cure 1993), coincidindo com a distribuição geográfica conhecida de C. arrudae (V. Bittrich, dados não publicados). O período de atividade de $E$. nigrohirta coincide com o período de pico da floração de C. arrudae: novembro a fevereiro. Na área da Serra da Calçada, E. nigrohirta foi coletada de dezembro a princípio de março. Em março, quando já haviam poucas flores de C. arrudae, E. nigrohirta foi observada apenas duas vezes (tendo sido observada 19 vezes entre janeiro e fevereiro). A coincidência no período de floração de $C$. arrudae e o período de atividade de E. nigrohirta reforça a idéia desta abelha como polinizadora desta espécie de planta.

Provavelmente a diminuição nas freqüências de visitas de $A$. mellifera e E. nigrohirta nas flores de C. arrudae esteja relacionada à diminuição na produção de flores. No caso de E. nigrohirta, a diminuição na freqüência pode ser devida a uma provável interdependência entre o polinizador e a planta, já que o período de floração coincide com o período de atividade da abelha. No entanto, em $A$. mellifera, que é uma espécie perene e generalista, a diminuição se deve ao padrão de forrageamento desta espécie que prefere fontes de recursos em abundância (Seeley 1985).

A pouca variação na freqüência de $T$. spinipes, que também é perene e generalista, no decorrer da floração de $C$. arrudae pode ser explicada pelo tamanho desta abelha que coleta pouca quantidade de material em suas visitas e, portanto, mesmo com uma grande diminuição na disponibilidade de flores, os recursos apresentados ainda são suficientes para o forrageamento.

A alta taxa de visitação de meliponineos observada em C. arrudae também foi observada em outras espécies estudadas, porém, com pequena participação na polinização (Lopes \& Machado 1998). No entanto, em espécies como $C$. leprantha, $C$. renggerioides e C. panapanari os meliponineos mostraram-se de grande importância para a polinização (Bittrich \& Amaral 1997).

A especificidade de Clusia arrudae com relação ao seu polinizador, como ocorre em várias outras espécies, mostra a necessidade da preservação das espécies nativas de abelhas, assim como das espécies vegetais visando manter os vários sistemas polinizador-planta, e portanto, o equilíbrio entre os animais e plantas que apresentem mútua dependência.
Agradecimentos - Ao Dr. Fernando A. Silveira pelas discussões e apoio logístico, ao Dr. V. Bittrich pelas informações, a Rosiane do Carmo e Patrícia Santos pela ajuda nos trabalhos de campo e à Capes pela concessão da bolsa de mestrado a Roselaini M. Carmo.

\section{Referências bibliográficas}

ARMBRUSTER, W.S. 1984. The role of resin in Angiosperm pollination: ecological and chemical considerations. American Journal of Botany 71:1149-1160.

BAWA, K.S. 1983. Patterns of flowering in tropical plants. In Handbook of experimental pollination biology (C.E. Jones \& R.J. Littler, eds.). Van Nostrand, New York, p.394-410.

BITTRICH, V. \& AMARAL, M.C.E. 1996. Flower morphology and pollination biology of some Clusia species from the Gran Sabana (Venezuela). Kew Bulletin 51:681-694.

BITTRICH, V. \& AMARAL, M.C.E. 1997. Floral biology of some Clusia species from Central Amazonia. Kew Bulletin 52:617-635.

CORREIA, M.C.R. 1983. Contribuições ao estudo da biologia floral e do sistema de reprodução de Clusia fluminensis Pl. \& Tr. (Guttiferae). Dissertação de mestrado, Universidade Federal do Rio de Janeiro, Rio de Janeiro.

CORREIA, M.C.R., ORMOND, W.T., PINHEIRO, M.C.B. \& LIMA, H.A. 1999. Biologia da reprodução de Clusia lanceolata Camb. Hoehnea 26:61-72.

DAFNI, A. 1992. Pollination ecology - a practical approach. Oxford University Press, Oxford.

KÄPYLÄ, M. 1974. Diurnal flight activity in a mixed population of Aculeata (Hym.). Annual Entomology Fenology 40:61-69.

KIMSEY, L.S. 1982. Systematics of bees of the genus Eufriesea (Hymenoptera, Apidae). University of California Press, California.

LOKVAM, J. \& BRADDOCK, J.F. 1999. Anti-bacterial function in the sexually dimorphic pollinator rewards of Clusia grandiflora (Clusiaceae). Oecologia 119:534-540.

LOPES, A.V. \& MACHADO, I.C. 1998. Floral biology and reproductive ecology of Clusia nemorosa (Clusiaceae) in northeastern Brazil. Plant Systematics and Evolution 213:71-90.

MAÊDA, J.M. 1985. Manual para uso da câmara de Neubauer para contagem de pólen em espécies florestais. Universidade Federal do Rio de Janeiro, Rio de Janeiro.

MICHENER, C.D. 2000. The bees of the world. The Johns Hopkins University Press, Baltimore.

NOGUEIRA-NETO, P. 1997. Vida e criação de abelhas indígenas sem ferrão. Editora Nogueirapis, São Paulo. 
OLIVEIRA, P.E., GIBBS, P.E. \& BIANCHI, M. 1991. Pollination and breeding system of Vellozia squamata (Liliales, Velloziaceae) a species of the Brazilian cerrados. Botanica Acta 104:392-398.

OLIVEIRA, C.M.A., PORTO, A.M., BITTRICH, V., VENCATO, I. \& MARSAIOLI, A.J. 1996. Floral resins of Clusia spp.: chemical composition and biological function. Tetrahedron Letter 37:6427-6430.

OPLER, P.A. \& BAWA, K.S. 1978. Sex ratios in tropical forest trees. Evolution 32:812-821.

RAMÍREZ, W.B. \& GÓMEZ, L.D. 1978. Production of nectar and gums by flowers of Monstera deliciosa (Araceae) and of some species of Clusia (Guttiferae) collected by New World Trigona bees. Brenesia 14/15:407-412.
SEELEY, T.D. 1985. Honeybee Ecology - A study of adaptation in social life. Princeton University Press, New Jersey.

SILVEIRA, F.A. \& CURE, J.R. 1993. High-altitude bee fauna of southeastern Brazil: implications for biogeografic patterns (Hymenoptera: Apoidea). Studies on Neotropical Fauna and Enviroment 28:47-55.

SIMPSON, B.B. \& NEFF, J.L. 1981. Floral rewards: alternatives to pollen and nectar. Annuals of the Missouri Botanical Garden 68:301-322.

THOMSON, J.D. \& THOMSON, B.A. 1992. Pollen presentation and viability schedules in animal-pollinated plants: consequences for reproductive success. In Ecology and evolution of plant reproduction. New approaches (R. Wyatt, ed.). Chapman \& Hall, New York, p.1-24.

WILLSON, M.F. \& ÅGREN, J. 1989. Differential floral rewards and pollination by deceit in unisexual flower. Oikos 55:23-29. 